\title{
Estrategias Comunicativas de las Organizaciones No Gubernamentales
}

Communicative strategies of the Non Governmental Organizations

Maritza Sobrados León

Profesora del Programa de Doctorado "Periodismo y Sociedad" del Departamento de Periodismo II, Facultad de Comunicación, Universidad de Sevilla

Correo eletrónico: sobrados@us.es

Resumen

Las Organizaciones No Gubernamentales son una importante fuente de información para los medios de comunicación sobre diversos temas de alcance social donde el discurso oficial puede resultar frío e insuficiente. Para interactuar con los medios de comunicación, las ONG recurren a una serie de estrategias a fin de conseguir desde la sensibilización de la población al conocimiento racional sobre la realidad de los países en vías de desarrollo. En España, las ONG que trabajan con inmigrantes son un claro ejemplo de la evolución y consolidación de éstas como fuente alternativa. El crecimiento de la inmigración, del 2,3\% de la población española en 2000 al 9,3\% en 2006, ha propiciado esta evolución.

Palabras clave: ONG, medios de comunicación, España, inmigración.

Las Organizaciones sin ánimo de lucro, más conocidas como Organizaciones No Gubernamentales (ONG) y Organizaciones No Gubernamentales para el Desarrollo (ONGD), tienen una presencia importante en todo el mundo y su trabajo en favor de los colectivos y países más desfavorecidos es apoyada por gobiernos y organismos internacionales. Estas organizaciones tienen objetivos de lo más variados y la aplicación práctica de sus actividades, así como sus políticas de comunicación difieren unas de otras. Para comunicar eficazmente sus objetivos, las grandes organizaciones humanitarias tienen profesionales que desarrollan las adecuadas estrategias de comunicación; pero no ocurre lo mismo con las demás, que son la mayoría. En este artículo me voy a referir a las Organizaciones No Gubernamentales que trabajan únicamente con inmigrantes que, salvo algunas excepciones, se encuentran entre esa mayoría de asociaciones apenas organizadas en sus políticas de comunicación.

En las últimas décadas, la inmigración en España ha crecido de forma acelerada y esto ha propiciado el nacimiento de numerosas $\mathrm{ONG}$ que fijan sus objetivos en este colectivo. En Canarias, que en los últimos años ha recibido el mayor número de inmigración clandestina que llega a España, hay 65 ONG registradas, de las cuales 23 se dedican a la gestión de la inmigración. La importancia de su labor ha sido reconocida por el Gobierno español que ha multiplicado por dos en un par de años la partida (12 millones de euros) para este tipo de organizaciones. Así, la inmigración se ha convertido en un asunto de primer orden en la agenda política y mediática, por eso resulta interesante acercarse a las estrategias que desarrollan para interactuar con los medios de comunicación en la consecución de sus objetivos.

El crecimiento de las ONG es uno de los fenómenos más relevantes de los últimos años tanto en el panorama nacional como internacional. El trabajo que realizan es totalmente reconocida por la sociedad, aunque la repetida utilización de imágenes dramáticas y el uso de estrategias de mercadotecnia por parte de algunas ONG, han conseguido deteriorar en parte la imagen idílica de estas organizaciones. El marketing social es la vertiente del marketing abocada a la aplicación del criterio de eficacia 
1 La repercusión negativa de las estrategias publicitarias de algunas ONG alertó a las organizaciones europeas compro-metidas en actividades de cooperación al desarrollo de los pueblos del Tercer Mundo. Representantes de cerca de 700 ONG de Europa redactaran un código de conducta sobre la utilización de imágenes y mensajes, que fue aprobado por la Asamblea General del Comité de Enlace de las ONG europeas ante la empresarial en las organizaciones sin ánimo de lucro. La solidaridad se ha convertido en un producto más en el mercado y esto no ha estado exento de crítica ${ }^{1}$.

Aún así, desde hace tiempo se ha producido un acelerado crecimiento del movimiento de solidaridad en España enfocado a las más diversas áreas de intervención. Coinciden diversos autores que el crecimiento del llamado Tercer Sector en España se produce entre los años 1994 y 1995 debido a las sucesivas crisis de Ruanda, Somalía, Bosnia, Grandes Lagos y con la campaña del movimiento por el $0,7 \%$.

Entre los aspectos positivos del llamado Tercer Sector, Funes (1993) destaca su utilidad para detectar y atender las necesidades sociales con mayor rapidez que los organismos oficiales, posibilidad de generar una serie de soluciones más innovadoras y creativas que las respuestas institucionales, menor grado de burocratización que facilita la creación de nuevas estrategias, un grado de informalidad que les permite atender algunos problemas con mayor eficacia (tienen más facilidad para conectar con la base) y una mayor facilidad para acceder a la problemática social. En el caso de los inmigrantes, además, genera mayor confianza al tratarse de un organismo no público que puede detectar y penalizar situaciones irregulares.

\section{ONG pro inmigrantes en Andalucía}

Los movimientos migratorios constituyen una realidad que se encuentra muy presente en las políticas sociales, económicas, educativas y culturales de España y los medios de comunicación no son ajenas a ella. También muy presente en la agenda mediática, la inmigración, sobre todo su acelerado crecimiento en los últimos años, ha impulsado la aparición de ONG pro inmigrantes.

Según el Instituto Nacional de Estadística, a diciembre de 2006 el porcentaje de población extranjera en España era del 9,3 por ciento y en Andalucía se concentra el 11,8\% de esa población. El colectivo extranjero más numeroso es el marroquí, seguido de ecuatorianos, rumanos y colombianos, no sorprende por tanto que en los últimos años se haya reforzado el asociacionismo de algunos de estos colectivos, ni que hayan nacido numerosas organiza-ciones de asistencia al inmigrante para dar respuesta a una labor necesaria por la demostrada insuficiencia de los organismos oficiales, sobre todo en la atención de los recién llegados en situaciones precarias. Si en Canarias hay 23 organizaciones pro inmigrantes, en Andalucía, región que recibe también numerosas llegadas de inmigración clandestina, hay 17 asociaciones.

La intervención de organizaciones humanitarias en los continuos desembarcos clandestinos de inmigrantes en las Islas Canarias en los últimos años y anteriormente en las costas de Cádiz, son un claro ejemplo del importante trabajo que realizan estas organizaciones, que además asumen el reto de crear espacios de integración cultural y sensibilizar a la sociedad española.

En 1985, en Sevilla, se creó la primera organización en España con el fin específico de trabajar con la población inmigrante. Siete personas crearon Sevilla Acoge e instaron a otras provincias a seguir esta iniciativa, así nacen Málaga Acoge en 1989, Almería Acoge, Granada Acoge ... y en 1991 la Federación Andalucía Acoge, de la que Sevilla y Almería finalmente se desvinculan. Sevilla Acoge pertenece al Consorcio de Entidades para la Acción Integral con Migrantes, CEPAIM, con el 
que comparte sede. En la actualidad cuenta con 32 personas contratadas, 4 estudiantes en prácticas, 6 contratados en prácticas y 68 voluntarios, a los que hay que sumar $\operatorname{los} 18$ contratados por CEPAIM. Recientemente ha pasado de Asociación a Fundación, modelo que, según su secretario, Esteban Tabares, ofrece mayores ventajas fiscales, contables, así como mayor transparencia en el manejo del dinero.

El aumento del número de inmigrantes y la falta de asistencia social fue lo que movilizó a un grupo de personas para crear Málaga Acoge en 1989. Ahora trabajan 17 contratados y tienen 250 voluntarios. La asociación se plantea la asistencia en parcelas que el Estado no cubre, además de la reivindicación, la promoción y la sensibilización. Igualmente motivada por la necesidad de asistencia a los inmigrantes que cada vez llegaban en mayor número, en 1991 nace Algeciras Acoge, que actualmente cuenta con unos 30 trabajadores, 5 de ellos contratados. La asociación algecireña trabaja en 4 áreas: social, promoción, sensibilización y denuncia.

\section{Políticas de comunicación}

Según María Itatí ${ }^{2}$ la comunicación se volvió una herramienta clave de las organizaciones sin fines de lucro cuando encontrar patrocinadores, donantes y volun-tarios se convirtió en un problema: “...las ONG comenzaron a incorporar criterios de eficacia empresarial y a profesionalizar sus puestos directivos. Una de las decisiones más importantes de este cambio fue desarrollar planes de comunicación estratégicos: la importancia de la comunicación radica en que para ser reconocidos no basta con tener objetivos solidarios... Para ser reconocidos deben hacerse conocer y generar confianza en la sociedad. Solo a través de la comunicación podrán transmitir la imagen de la organización, que ésta sea un reflejo fiel a sus valores".

Para Itatí los planes de comunicación de las ONG se caracterizan por cumplir los siguientes pasos:

1 Determinan los objetivos de comunicación. Hay que plantearse qué se busca comunicar de acuerdo a los efectos que se quiere producir en la sociedad. Los objetivos deben ser realistas y expresarse de forma cuantitativa para después verificar los resultados.

2 Decidir a quién se dirige la comunicación. Los objetivos deben estar vinculados a los públicos a los que están dirigidos, a fin de diseñar la estrategia de comunicación más adecuada. Por ejemplo, no será la misma estrategia para que una ONG se haga conocida en el ámbito empresarial que para incentivar la colaboración de voluntarios.

3 Definir la idea a transmitir. El mensaje debe ser persuasivo para la satisfacción del objetivo. Por ejemplo, si el objetivo es sumar voluntarios, el mensaje deberá motivar a los destinatarios para que quieran participar en el trabajo de la ONG.

4 Fijar el presupuesto. Es necesario conocer de qué cantidad se dispone para cada acción concreta. No es imprescindible disponer de un presupuesto elevado para poner en marcha un buen plan de comunicación, lo importante es concienciarse de la necesidad de destinar recursos para ello.

5 Seleccionar los medios apropiados y su frecuencia de utilización. Para hacer la selección adecuado es necesario conocer los hábitos del público al que se dirige la comunicación. Los
2 ITATÍ, M: "Las ONG y la comunicación de sus objetivos", en www.relacionespublicas.com/ las-ong-y-la-comunicacion-desus-objetivos.htm 
canales de comunicación que se suelen contemplar dentro del plan de medios pueden ser personalizados (publicitarios, fuera o dentro de Internet, marketing telefónico o relaciones públicas), masivos (revistas, boletines, presenta-ciones de las ONG) y los grandes medios de comunicación (prensa, radio y televisión).

6 Ejecutar el plan de medios y medir su impacto. Es funda-mental finalizar la campaña si los objetivos se cumplieron o no y cuáles son las razones. Así se pueden corregir errores y reorientar los objetivos.

Más allá de conseguir los objetivos propios de la organización y los propuestos en las campañas, subsiste una relación directa de las ONG con los medios de comunicación, que ha ido evolucio-nando con el tiempo hasta el punto de convertir a éstas en una de las principales fuentes de información sobre cuestiones sociales. La información oficial resulta insuficiente para los medios que han encontrado en estas organizaciones la alternativa para poder contrastar la información recibida.

En un estudio sobre la presencia de las ONG de desarrollo, ONGD, en la agenda de los medios, González $z^{3}$ asegura que las temáticas en las que estas organizaciones han pretendido ser fuentes de información han variado según las necesidades que iban surgiendo. Así, en una primera etapa comunicativa, la temática giraba en torno a la propia organización, quiénes eran y qué hacían. La novedad del movimiento fue el principal factor que favoreció la noticiabili-

${ }^{3}$ GONZÁLEZ LUIS, H.: Evolución temática de las ONGDS como fuentes de los medios de comunicación, en www.unav.es/ $\mathrm{fcom} / \mathrm{cicom} / \mathrm{pdf} / \mathrm{g} 1$.estrategias/ Hildegart\%20González.pdf dad de las primeras informaciones sobre ellas. El segundo motivo que las impulsó a estar presentes en los medios fue la búsqueda de apoyo público, luego surgió la necesidad de captar nuevos donantes y el número de voluntarios. A estas alturas los periodistas rechazaban cada vez con mayor agilidad las notas de prensa que podían catalogarse como propaganda institucional y persuasiva.

Según la citada autora, a finales de los noventa las grandes ONGD comenzaron a plantearse la producción de información útil para los periodistas, lo que exigía una profesionalización en los departa-mentos de comunicación poco habitual en ese momento. Sus mensajes se centraron en avisar sobre una situación de riesgo que podía derivar en catástrofe, información que fue bien recibida por los medios, ya que las ONGD se convertían en fuentes privilegiadas que advertían del origen de las noticias. Pero, saturados de posibles conflictos, poco a poco los medios fueron perdiendo interés por estos temas.

Con el fin de fortalecer su papel, las ONGD comenzaron a aportar soluciones en el debate sobre la erradicación de la pobreza y los medios informativos incorporaron este discurso con un protagonismo similar al concedido a agentes de desarrollo de reconocido prestigio, como la ONU, FAO, UNICEF, etc. Las últimas estrategias comunica-tivas consisten en ser fuente disponible para los medios para mejorar cualquier información sobre las realidades de los países en vías de desarrollo. La intencionalidad de estos mensajes es informativa y la temática, se centra en contar lo que sucede, la ONGD pasa a un segundo plano. Pero, como advierte González, sólo las grandes ONGD han descubierto que si los mensajes que envían a prensa, radio y televisión son informativos, aumenta su repercusión mediática y contribuyen a mejorar el conocimiento racional sobre la realidad de los países del Sur.

Si bien las necesidades de las Organizaciones No Gubernamenta- 
les han permitido su evolución como fuentes informativas, en el caso de la inmigración, las necesidades de los medios de comunicación fueron determinantes para que estas organizaciones se erigieran en fuente alternativa. La voz de los inmigrantes no tiene cabida en un sistema de producción que legitima y privilegia a las fuentes mejor organizadas, que normalmente son las gubernamentales y otros grupos de influencia social. Estos grupos de élite producen materiales informativos adaptados a los requerimientos de la producción periodística y los medios acuden rutinariamente a ellos porque les garantizan un flujo continuo y fiable de noticias.

La selección de los temas referidos a la inmigración está orientada a los aspectos más estereotipados: la inmigración ilegal, los delitos, las relaciones conflictivas, la regularización, etc., temas en los que la policía $\mathrm{y}$ las instituciones gubernamentales suelen ser fuentes principales. Raras veces los medios rompen con la rutina que permiten que la mayoría de la sociedad tenga una percepción de los hechos coincidente con la institucional y con ello limita al receptor la posibilidad de tener una visión más amplia y contrastada de los hechos de actualidad.

Las organizaciones humanitarias tienen el reconocimiento público como expertas en inmigración y esto le da autoridad ante los medios de comunicación para convertirse en fuentes. También la necesidad de dar a la noticia un lado más humano y contrastar la fría información institucional son los aspectos que han permitido la legitimación de las ONG como fuentes y su inclusión en el proceso de rutinización informativa. El tratamiento informativo de la inmigración, tan difícil de abordar adecuadamente, ha cambiado gracias a las ONG que dan un punto de vista diferente, más cercano a los intereses de los inmigrados.

En el caso de Algeciras Acoge, fue fundamental estar en el lugar del conflicto $^{4}$. En un momento en que la llegada de pateras se hizo diaria, Algeciras Acoge vino a llenar un hueco importante como fuente alternativa al discurso institucional, posibilitó el toque humano de la noticia. El hecho de que no había nadie más para contrarrestar lo dicho por la Administración hizo que se consolidara como fuente y se produjera un cambio en el discurso mediático.

Algeciras Acoge pasó por diversas etapas de reacción ante los medios. Al principio no sabían como actuar, había descontrol, inseguridad, no se planificaba el discurso, en ocasiones llegaron incluso a plantearse no hablar sobre inmigración, porque no se consideran especialistas. Después vendría una segunda etapa en la que se acostumbraron a los medios, aparecían en la prensa todos los días con temas de denuncia, actos reivindicativos. Eran los primeros años de la década de los noventa, muchos medios locales, nacionales e internacionales se acercaban a la asociación para preguntarles su opinión, se convirtieron en punto de referencia en temas de inmigración ilegal.

Luego llegaría la calma, coincidiendo con la disminución de entradas ilegales por el Estrecho de Gibraltar. El conflicto se ha trasladado a las Islas Canarias y el interés mediático también. Es una etapa en la que aparecer en los medios informativos no es una prioridad, se limitan a responder a las demandas de los periodistas, son raras las notas de prensa que elaboran o ruedas de prensa que convocan. Sin embargo, reconocen la importancia de la comunicación, de hecho, tienen tres portavoces; no tener un periodista es una cuestión económica, para ellos
${ }^{4}$ Algeciras, es la ciudad principal de la Comarca del Campo de Gibraltar, ubicada en la provincia de Cádiz, donde llegaban casi a diario pateras (pequeñas embarcaciones) con inmigrantes a través del Estrecho de Gibraltar en la década de los 90. Esta situación se continúa dando aunque el número ha disminuido notablemente. En los últimos años, los desembarcos clandes-tinos se producen principalmente en las costas de las Islas Canarias, que ya en 2002 doblaba el número de entradas por el Estrecho. 
es fundamental, pero es un objetivo a largo plazo.

Todas las ONG citadas han llegado a ser fuente de referencia, son la voz de los inmigrantes para los periodistas. Que las ONG se hayan situado entre las principales fuentes en el asunto migratorio es un logro, pero es necesario conseguir un cambio de actitud de los medios para que sean capaces de enfrentarse a una visión superficial y estereotipada de la inmigración. Tarea sin duda difícil, que sólo parece posible con el compromiso personal de aquellos periodistas concienciados con las problemáticas sociales, lo que Erro (2002) 1lama comunicación solidaria.

\section{La comunicación, elemento clave}

Además de la labor primaria de atención e información al inmigrante, el objetivo de toda ONG es conseguir un cambio de actitud por parte de la sociedad con los colectivos desfavorecidos en los que centran su trabajo. Para la consecución de este objetivo la comunicación se torna en un elemento de enorme utilidad. Las estrategias de comunicación deben ser fruto de la interacción de la dirección y el departamento de comunicación para reflejar fielmente los fines de la organización.

En la mayoría de ONG la labor de comunicación no está realizada por profesionales sino por miembros de la organización que a menudo comparten esta función con otras. De las organizaciones andaluzas citadas, sólo la Federación tiene un gabinete de comunicación consolidado; en Sevilla Acoge desde hace pocos meses hay una periodista contratada por CEPAIM, así que apenas se está organizando el tema de la comunicación, que en el organigrama aparece dependiente directamente de la dirección y transversal a todas las áreas.

El gabinete de comunicación de la Federación Andalucía Acoge funciona desde el año 2001. Su responsable, Marta Aguilar, destaca una importante evolución entre los miembros de la organización: “Al principio habían muchas reticencias hacia la comunicación, pero han ido educándose y ven que es positivo para conseguir los objetivos que se plantean. Muchas veces se ve mal a la prensa, por el morbo con el que a veces se tratan algunos temas, pero sin duda es un aliado más que un enemigo".

Hay un antes y un después del gabinete de comunicación en la Federación. Contratar a una periodista marcó un hito con respecto al discurso público y la visualización de la organización. Antes sólo se daba respuesta a la demanda de los medios, ahora se plantea cómo debe ser el discurso, porque cuando se tiene una herramienta de comunicación también es posible ofertar información.

Las dos restantes asociaciones consideran a la comunicación como algo fundamental, aunque no prioritario. La escasez de medios económicos es lo que les impide poner en marcha un departamento de comunicación o un gabinete de prensa. Entre los proyectos de Málaga Acoge para el próximo año esta la creación de un gabinete de prensa. Para esta asociación la comunicación es un medio no un objetivo y valoran su importancia en la medida en que consideran la reivindicación como su labor más trascendente.

Sevilla Acoge tiene como finalidad principal la ayuda, promoción y defensa del inmigrante, pero como objetivo general se plantean el cambio social y para ello, fundamentalmente, sus estrategias comunicativas están dirigidas a la sensibilización de la población a varios niveles, en 
primer lugar responden a las demandas que les llegan para participar en actividades y organizar otras, como mesas redondas y conferencias; en segundo lugar están las propias actividades que realiza la asociación, como publicaciones de investigaciones, folletos o la página web en la que se incluye un boletín de noticias.

Todas las ONG citadas cuentan con una página web con información sobre la organización y sus objetivos. Hace unas décadas no se incluía Internet entre las estrategias de comunicación pero hoy casi todas las organizaciones sin ánimo de lucro disponen de pagina web; no entro en cuestionar la calidad y pertinencia del tipo de información ofrecida,${ }^{5}$ pero tener una página web es un elemento importante aunque insuficiente para cumplir con los objetivos de comunicación.

También hacia la sensibilización a los medios y la población en general, están dirigidas las estrategias comunicativas de la Federación andaluza. Tienen tres flancos de acción: Fuentes, medio y receptor. Las fuentes, que en este tema son principalmente cuerpos de seguridad del estado, administración, partidos políticos, ONG y empresarios, condicionan el producto final, por eso están elaborando una guía de fuentes para diversificar las que usualmente son consultadas, que al ser siempre las mismas dificulta la objetividad de la noticia. En cuanto al medio en sí, se trata de formar al periodista a través de cursos. La otra línea de acción es la formación de una conciencia crítica del receptor, por ejemplo tienen un taller de prensa con alumnos de Educación Secundaria que funciona desde hace tres años; pero la sensibilización de la población se hace fundamentalmente a través de los medios de comunicación.

Las ONG aparecen con frecuen- cia en los medios de comunicación y esto ha favorecido la captación de socios y voluntarios, además de la difusión de su labor y fines a toda la sociedad. Dice Fernández Torres ${ }^{6}$ que toda persona o grupos de personas que desean mantener una presencia en los medios de comunicación han de recurrir a diversas estrategias de comunicación y que esto conlleva que se incrementen las actividades espectaculares o sensacionales de las organizaciones en detrimento de otras acciones más informativas y racionales.

Lo cierto es que no es tarea sencilla que las ONG puedan transmitir su mensaje a través de los medios de comunicación, aunque para algunas es más fácil porque cuentan con estrategias para manejarse en la dinámica informativa de los medios. Ocurre que las organizaciones de economía limitada no tienen profesionales para plantear estrategias comunicativas adecuadas y conseguir que los medios difundan sus mensajes. Así, como asegura Fernández Torres, los medios juegan un papel fundamental en el momento de presentar unas ONG y hacer desaparecer otras del sistema informativo. Esta presencia depende mucho del tipo de acción realizada por la $\mathrm{ONG}$, ya que tendrá más posibilidades la que trabaje con urgencias humanitarias (situación que llama mucho la atención), que aquella dedicada al desarrollo.

Entre las técnicas utilizadas por las organizaciones sin fines de lucro para asegurar su presencia en los medios informativos, Castillo Esparcia $^{7}$ cita la realización de acontecimientos apoyados por personajes famosos, la realización de actos y acciones espectaculares (Greenpeace) o la elaboración esmerada de informaciones sobre las actividades ejecutadas por la organización (Médicos sin Fronteras).
5 En un estudio sobre Internet y las ONG, Pérez Martínez, en www.saladeprensa.org/ art682.htm, se refiere por ejemplo al idioma. Según este estudio, el 72 por ciento de los sitios web están redactados en castellano únicamente. Esta cuestión es sumamente importante en la información que ofrecen las $\mathrm{ONG}$ pro inmigrantes ya que ésta está dirigida a colectivos extranjeros que no necesariamente conocen el castellano, algo que constituye una barrera para el entendimiento y una limitación para los objetivos de comunicación.

${ }^{6}$ FERNÁNDEZ TORRES, M. J., La estrategia comunicativa de las Organizaciones No

Gubernamentales, en www. campusred.net/forouniversitario/ pdfs / comunicaciones / comunicacion

corporativa_e_institucional/ Fernandez_Torres.pdf\#search= $\% 221$ a\%20estrategia\% 20 comunicativa $\% 20$ 
Las estrategias de comunicación no deben limitarse al lanzamiento indiscriminado de información con el fin de aparecer en los medios. Teniendo en cuenta que hay un nivel alto de saturación informativa en la sociedad que puede afectar a la eficacia en la recepción del mensaje, es necesario crear información veraz que conecte con el interés de la población. Carlos Ongallo (2000) resume las ventajas de una comunicación bien dirigida: crea sentimientos de adhesión (socios y voluntarios), optimiza los recursos, sensibiliza a la población, motiva, favorece el desarrollo y potencia la solidaridad.

Insertadas en una sociedad mediatizada, las ONG se convierten en actores sociales de primer orden y entran en la dinámica informativa, en la que necesitan de los medios de comunicación para mantener su estatus. Para ello, deben adoptar una actitud abierta, de comunicación fluida y constante con ellos.

Según Castillo Esparcia ${ }^{8}$ la relación con los medios debe basare en una serie de pilares:

1 Ánimo de informar, pero sin olvidar nunca los intereses de la organización. Esto no quiere decir que se vean obligados a realizar o emitir información parcial, sino que sean informaciones noticiosas para los medios, y en consecuencia, puedan incluirlas en su espacio.

2 Establecer una comunicación única y abierta con los periodistas. Establecer una buena relación con los periodistas tiene dos consecuencias positivas: que la ONG se convierta en fuente de información y que pasen a ser interlocutores válidos para los periodistas.

3 Una colaboración ágil y eficaz cuando los medios lo soliciten.

${ }^{8}$ Op. cit. riodistas disponen de un tiempo reducido, cuanto antes se les dé la información, más lo agradecerán.

4 La información debe ser siempre veraz, sino se corre el riesgo de dejar de ser interlocutor válido. La credibilidad cuesta mucho ganarla y poco perderla.

5 La transparencia debe ser el modelo de comportamiento.

Las ONG en los medios de comunicación

La opinión pública se conforma mediante una actividad selectiva de los temas ejercida por los medios de comunicación. La sociedad acepta ese papel selector que tienen los medios porque han alcanzado un estatus social y gozan de suficiente credibilidad para que el público acepte la valoración previa que hacen de los hechos de actualidad. Luhmann (2000) concluye que la sociedad deja en manos del sistema de los mass media su observación.

Como resultado de la concepción de lo que es noticia para los medios, estos aplican unos criterios de selección de los temas para captar la atención del receptor. Böckelmann (1983, p 65) enumera como criterios selectivos "la referencia a lo personal, a lo privado y a lo íntimo, los síntomas del éxito en el aspecto de la cuantificación y de la atribución personal; la novedad de los acontecimientos; los síntomas del ejercicio del poder político; la distinción entre normalidad y anormalidad; la violencia, la agresividad y el dolor (que se considera uno de los criterios más elementales de selección); la competición; la referencia al incremento de la propiedad y del enriquecimiento en la vida individual; las crisis y los síntomas de crisis; la observación de lo extraordinario, de lo singular y lo exótico".

En el caso de la inmigración, 
ocurre que es un tema rodeado de aspectos excepcionales que atraen la atención de los medios. Erro (2002) considera que la naturaleza de los medios informativos y el peso del espectáculo y del simulacro en el mundo de la imagen es una traba para las relaciones entre medios y ONG. Al final, algunas organizaciones se ven abocadas a adaptarse a las rutinas de producción de los medios y su preferencia por los acontecimientos dramáticos y de gran impacto visual.

De las ONG andaluzas mencionadas, sólo la Federación utiliza la estrategia de adecuar sus informaciones a los criterios de noticiabilidad de los medios. Su responsable de comunicación reconoce que se intenta buscar criterios de novedad y excepciona-lidad, pero siempre guardando los principios de la organización: "Nuestra labor está dirigida hacia el desarrollo y la integración y hacia esa finalidad está orientado el trabajo de comunicación. Pero, por ejemplo, si una información va a ser más noticia la semana que viene que hoy, la adaptamos. Tenemos un código que se intenta cumplir, la comunicación es un instrumento, pero no para captar socios a cualquier precio, el objetivo final no es ese, si eso va a tener consecuencias negativas como estereotipar o estigmatizar la inmigración entonces no se hace, el fin no justifica los medios".

Las organizaciones no lucrativas son conocidas principalmente por su labor en situaciones de emergencia, más difícil es llegar a la agenda de los medios con el trabajo cotidiano. Los hechos cotidianos no suelen interesar a los medios, aunque algunos le dan más cobertura que otros, y esto tiene que ver con el hecho de que la inmigración se ha convertido en una arma política y los medios en aliados de los políticos y sus intereses.
Para asegurar una relación sólida y fructífera con los medios informativos, las ONG necesitan encontrar las herramientas adecuadas. Para Ongallo (2000), las herramientas de comunicación son elementos instrumentales que persiguen poner en contacto la organización con la población, mejorar la interacción entre grupos y transmitir información. Las ONG no serían nada sin la capacidad de comunicación con el entorno.

Como ya he señalado, la mayoría de las organizaciones pro inmigrantes no tienen gabinetes de comunicación, pero son conscientes de las posibilidades que supone una buena gestión de la comunicación. Por eso, aunque no cuenten con profesionales, designan personas para que actúen como portavoces de la asociación ante los medios. Pero las ONG no siempre consiguen que los medios publiquen las noticias como ellos quisieran. A veces las noticias se tergiversan porque se tiende a condensar y aunque el mensaje esencial no se trastoca, el tema de la inmigración en sí tiene mal tratamiento en el lenguaje y un continuo referente a lo negativo. La falta de especialización del periodista se nota, la inmigración es cada vez un tema más complejo que exige, entre otras cosas, un conocimiento de la legislación.

\section{Conclusiones}

El crecimiento de las Organizaciones No Gubernamentales es uno de los fenómenos más característicos de la sociedad contemporánea. La necesidad de sensibilizar a la población y dar a conocer la realidad de los países en vías de desarrollo han permitido el desarrollo en los últimos años del marketing aplicado a organizaciones sin fines de lucro. A diferencia de otro tipo de organi- 
zaciones o asociaciones, las $\mathrm{ONG}$ venden una idea de solidaridad, de ayuda, de cubrir las necesidades más acuciantes de los más desfavorecidos, por eso una coherente política de comunicación de su imagen y objetivos es fundamental. Cada vez más estas organizaciones son conscientes de la necesidad de contar con profesionales de la comunicación para alcanzar sus fines, aunque no todas se lo pueden permitir.

Las Organizaciones No Gubernamentales han ido evolucionando como fuentes de información para los medios de comunicación. Un claro ejemplo es el de las organizaciones pro inmigrantes; en este caso, fue la necesidad de los medios de contar con un discurso alternativo a la información oficial, la que permitió que estas organizaciones se convirtieran en una de las principales fuentes en el tema de la inmigración. El sistema de producción informativa legitima y privilegia a las fuentes mejor organizadas, que normalmente son las gubernamentales y otros grupos de influencia social, en la que los inmigrantes parecen no tener cabida. Las ONG dedicadas a la gestión de la inmigración se convierten en la voz de los inmigrantes y alcanzan el reconocimiento de los medios y la sociedad como expertas en inmigración. El periodista busca en las ONG el punto de vista más humano ante la fría información institucional, y consolida a estas organizaciones como fuente informativa.

Para conseguir sus objetivos, las organizaciones humanitarias necesitan relacionarse con los medios de comunicación y necesitan que esta relación sea sólida y fructífera, por eso, muchas veces se ven abocadas a adaptarse a las rutinas de producción de los medios y su preferencia por los acontecimientos dramáticos y de gran impacto visual. Lo cotidiano no es noticia.
Es importante que las organizaciones sin fines lucrativos sean reconocidas y produzcan confianza en la población y para ello deben mantener su presencia en los medios de comunicación, pero el fin no debe ser aparecer en los medios a cualquier precio; la información que generen debe ser veraz y conectar con el interés de la sociedad. Una buena estrategia de comunicación consigue crear sentimientos de adhesión, optimiza los recursos, sensibiliza a la población, motiva, favorece el desarrollo y potencia la solidaridad.

\section{Abstract}

The Non Governmental Organizations are an important source of information for the mass media on diverse topics of social scope where the official speech can turn out to be cold and insufficient. In order to interact with the mass media, the ONG resort to a series of strategies in order to obtain from the sensibility of the population up to the rational knowledge of the realities of the countries in routes of development. In Spain the ONG that they work with immigrants they are a clear example of the evolution and consolidation of these as alternative source. The growth of the immigration, of $2,3 \%$ of the spanish population in 2000 to $9,3 \%$ in 2006, has propitiated this evolution.

Keywords: ONG, mass media, Spain, immigration.

\section{Referências}

BÖCKELMANN, F., Formación y funciones sociales de la opinión pública. Gustavo Gili, Barcelona, 1983.

CASTILLO ESPARCIA, A., Las ONGs como fuentes informativas de los medios de comunicación,en www.portalcomunicacion.

com/dialeg/paper/pdf/47_esparcia.pdf

ERRO, J., Comunicación, desarrollo y ONG. Hegia, Bilbao, 2002.

FERNÁNDEZ TORRES, M.J., La estrategia comunicativa de las Organizaciones No Gubernamentales, en www.campusred.net/ forouniversitario/pdfs/comunicaciones/ comunicacioncorporativa_e_institucional/ Fernandez_Torres.pdf\#search $=\% 221 \mathrm{a} \% 20$ 
estrategia\%20comunicativa\%20.

FUNES, M. J., "Las organizaciones voluntarias en el proceso de la sociedad civil", en Sistema n 117, noviembre 1993.

GARCIA IZQUIERDO, B., Nuevos socios para nuevas ONGD: Un modelo para involucrar a los ciudadanos en las ONGD. Universidad de Deusto, Bilbao, 2001.

GONZÁLEZ LUIS, H., Evolución temática de las ONGDS como fuentes de los medios de comunicación, en www.unav.es/fcom/cicom/pdf/ g1.estrategias/Hildegart\%20Gonzalez.pdf IBARRA, P. Y TEJERINA, B., Los movimientos sociales, transformaciones políticas y cambio cultural. Trotta, Madrid, 1998.

ITATÍ GARBERI, M.: Las ONG y la comunicación de sus objetivos, en www.

lasrelacionespublicaas.con/las_ong_y_la_ comunicacion_de_sus_objetivos.htm LUHMANN, N., La realidad de los medios de masas. Anthropos, Barcelona, 2000.
ONGALLO, C., Manual de Comunicación. Dyckinson, S.L., Madrid, 2000.

PÉREZ DE ARMIÑO, C.: Diccionario de acción humanitaria y cooperación al desarrollo. Icaria, Barcelona, 2002.

PÉREZ, V.., Internet y la comunicación alternativa en las Organizaciones No Gubernamentales, en www.saladeprensa.org/art682.htm

VILLAFANE, J., Imagen positiva. Gestión estratégica de la imagen de las empresas. Ediciones Pirámide, Madrid, 1993.

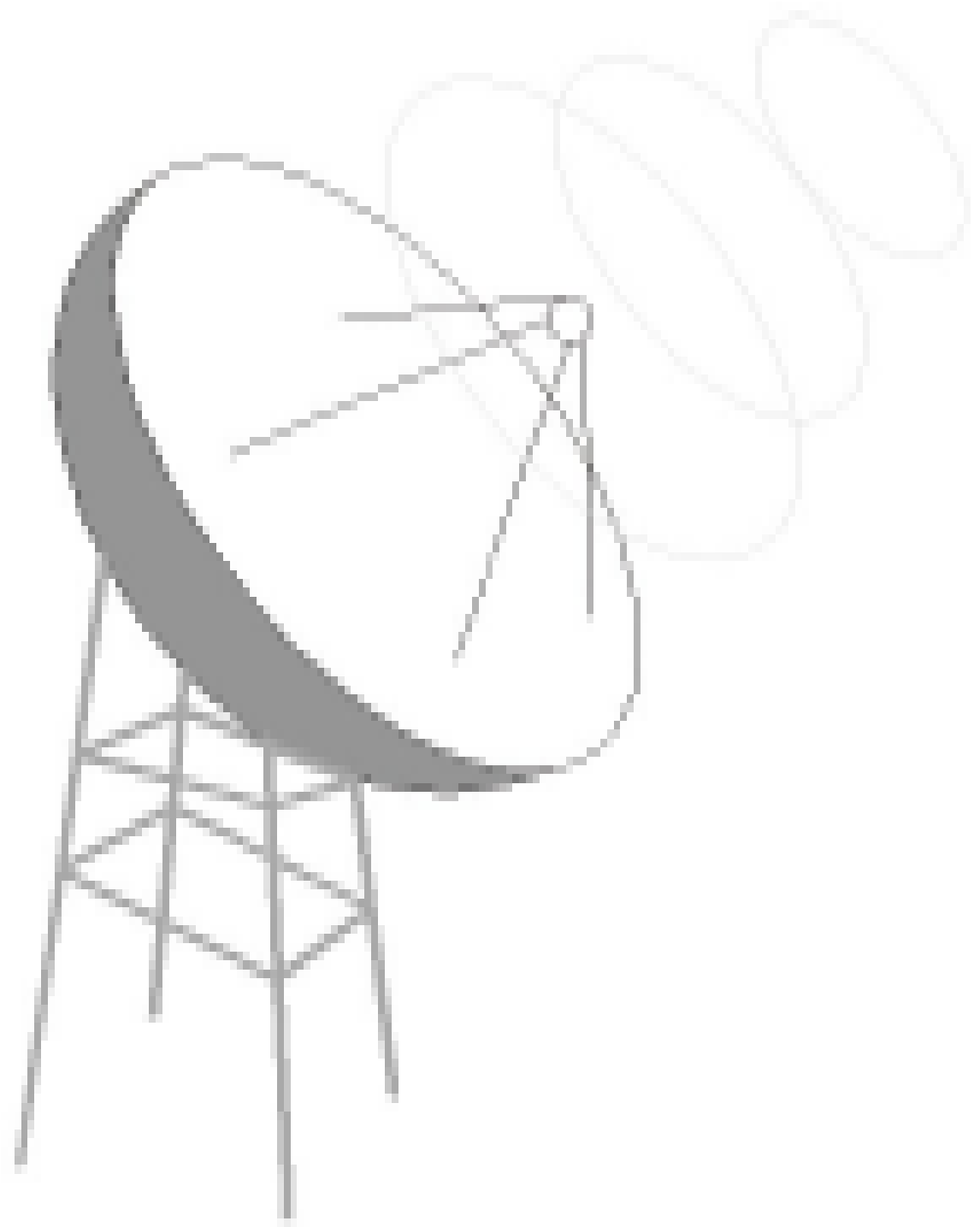

